\title{
Re: Infection control in burn patients: are fungal infections underestimated?
}

\section{David J Dries}

\author{
Address: Regions Hospital, St Paul, MN, USA \\ Email: David J Dries - david.j.dries@healthpartners.com
}

Published: 31 October 2009

Scandinavian Journal of Trauma, Resuscitation and Emergency Medicine 2009, 17:56 doi:10.1 186/1757-724I17-56

This article is available from: http://www.sjtrem.com/content//7/I/56

(c) 2009 Dries; licensee BioMed Central Ltd.

This is an Open Access article distributed under the terms of the Creative Commons Attribution License (http://creativecommons.org/licenses/by/2.0), which permits unrestricted use, distribution, and reproduction in any medium, provided the original work is properly cited.
Received: 12 October 2009

Accepted: 31 October 2009

\begin{abstract}
A response to Struck MF. Infection control in burn patients: are fungal infections underestimated? Scand J Trauma Resusc Emerg Med. 2009 Oct 9; I7(I):5 I. [Epub ahead of print] PubMed PMID: 19818134.
\end{abstract}

Dr. Struck [1] appropriately points out the importance of infecting agents apart from bacteria in the burn-injured patient. Burn patients are frequently cited as having the highest risk for invasive fungal infection as the burn wound provides an ideal portal for invasive infection while inducing immune dysfunction. Management of large burns exposes patients to risks identified in other patient groups including central venous lines, urinary catheters, prolonged mechanical ventilation and broadspectrum antibiotics.

Unfortunately, it is difficult to determine the true incidence and significance of fungal infections in the burn population. Contamination of urine, respiratory tract and skin by organisms such as Candida albicans is extremely common. Criteria for identifying true infection in the setting of burns remain unclear. Clinical findings, such as fever, may not be discriminatory to help identify invasive infection in burn patients. Specific definitions for burn/ wound infection rely heavily on wound appearance; fungal infection, in contrast, is notoriously difficult to diagnose on clinical findings alone. At present, a wide variety of practices exist among major North American burn centers to address this problem.
The American Burn Association recently published a review of burn patients with positive fungal cultures [2]. In all, positive cultures were seen in approximately $6 \%$ of 7,000 total admissions reviewed by reporting facilities. The incidence of positive fungal cultures varied widely, ranging from between $0.7 \%$ and $24 \%$ of patients treated at individual burn centers. There was no consistent pattern of treatment even if organisms were identified in the bloodstream. The majority of positive cultures came from the wound and respiratory tract (Figure 1).

When logistic regression was employed to examine factors relating to mortality, age, burn size and inhalation injury showed positive correlation. A positive culture of mold or Aspergillus was also predictive of death. Each treated fungal culture was associated with an increased hospital length of stay by nearly eight days. Surprising in this data was a high use of TPN, immunosuppressive agents and the presence of malignancy. In summary, positive fungal cultures are common in burns. Clinical significance must be better defined. At present, there is no consistent indication for prophylaxis. Aggressive wound debridement and avoidance of central venous catheters, parenteral nutrition and other immunosuppressive agents as possible can be recommended. 


\section{Sites From Which Fungal Organisms Were Cultured}

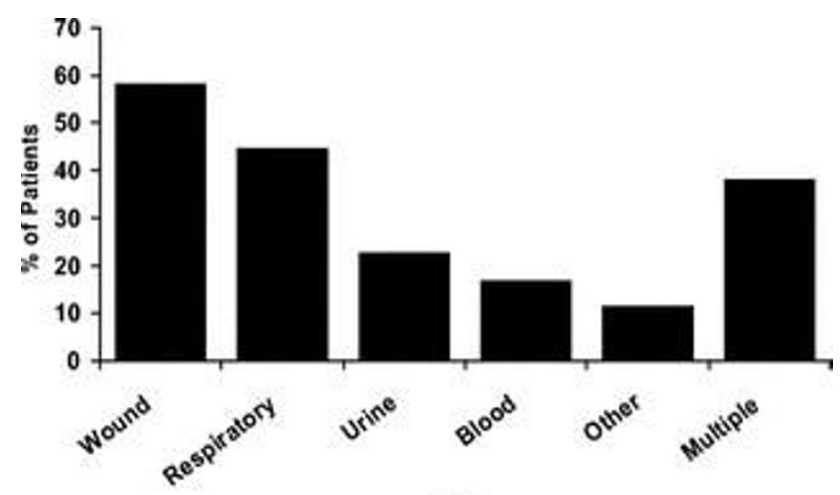

Site

Figure I

Sites From Which Fungal Organisms Were Cultured. (C) J Burn Care Res 2008; 29:213-221.

In my practice, I will treat positive fungal blood cultures. I will not treat positive sputum cultures unless a quantitative threshold for pneumonia is reached. Finally, I do not consider prophylaxis given the equivocal impact on mortality unless a patient has multiple risk factors [3-5].

\section{References}

I. Struck MF: Infection control in burn patients: are fungal infections underestimated? Scand J Trauma Resusc Emerg Med 2009 in press.

2. Ballard J, Edelman L, Saffle J, et al.: Positive fungal cultures in burn patients: A multicenter review. I Burn Care Res 2008, 29:2I3-22I.

3. Golan Y, Wolf MP, Pauker SG, et al.: Empirical anti-Candida therapy among selected patients in the intensive care unit: $A$ cost-effectiveness analysis. Ann Intern Med 2005, I 43:857-869.

4. Wood GC, Mueller EW, Croce MA, et al.: Candida sp. isolated from bronchoalveolar lavage: Clinical significance in critically ill trauma patients. Intensive Care Med 2006, 32:599-603.

5. Vardakas KZ, Samonis G, Michalopoulos A, et al.: Antifungal prophylaxis with azoles in high-risk, surgical intensive care unit patients: A meta-analysis of randomized, placebo-controlled trials. Crit Care Med 2006, 34:1216-1224.
Publish with Bio Med Central and every scientist can read your work free of charge

"BioMed Central will be the most significant development for disseminating the results of biomedical research in our lifetime. "

Sir Paul Nurse, Cancer Research UK

Your research papers will be:

- available free of charge to the entire biomedical community

- peer reviewed and published immediately upon acceptance

- cited in PubMed and archived on PubMed Central

- yours - you keep the copyright
BioMedcentral 